\title{
Dental reform in Israel's National Health Insurance Law has helped children and their families, but what's next?
}

\author{
Carlos Quiñonez
}

\begin{abstract}
Through a nationally-representative survey of 6 year-old children, Natapov, Sasson and Zusman demonstrate that the 2010 dental reform to the National Health Insurance Law (NHIL) has helped to improve the oral health of children in Israel. While the prevalence of dental caries (tooth decay) in Israel's children has remained relatively stable over time, compared to previous surveys, children now have more treated than untreated disease, suggesting that the NHIL reform has increased utilization and access to dental care, and arguably improved the quality of life of children and their families. Even though inequalities in oral health remain, universal coverage for children in Isreal is a positive development; yet for further improvements in oral health to materialize, attention will arguably need to be paid to broader preventive measures (e.g. drinking water fluoridation, oral disease prevention and oral health promotion in primary care), and more importantly, to the social determinants of health (e.g. income security, fair income distribution, food security).
\end{abstract}

\section{Background}

In their article, "Does the dental health of 6-year-olds reflect the reform of the Israeli dental care system?", Natapov, Sasson and Zusman [1] detail observable changes to the oral health of children since a 2010 reform included dental care for children in Israel's National Health Insurance Law (NHIL). The NHIL is a universal system of health insurance implemented in 1994/5 and delivered through four Health Maintenance Organizations. Before this reform, Israel was actually similar to my country, Canada, in two ways: 1 . dental care was not included in its national system of health insurance, with coverage limited to surgical and other basic dental services for those with specific medical conditions (e.g. trauma and cancer); and 2. the majority of dental care was paid for out-of-pocket, leading to systematic, unjust, and preventable differences in oral health and access to dental care between social groups based on the ability to pay. To be sure, as Natapov, Sasson and Zusman note, such a state of affairs was nothing short of a "market

Correspondence: carlos.quinonez@utoronto.ca

Dental Public Health, Faculty of Dentistry, University of Toronto, Toronto, Canada

(c) The Author(s). 2016 Open Access This article is distributed under the terms of the Creative Commons Attribution 4.0 International License (http://creativecommons.org/licenses/by/4.0/, which permits unrestricted use, distribution, and reproduction in any medium, provided you give appropriate credit to the original author(s) and the source, provide a link to the Creative Commons license, and indicate if changes were made. The Creative Commons Public Domain Dedication waiver (http://creativecommons.org/publicdomain/zero/1.0/) applies to the data made available in this article, unless otherwise stated. 
found that there was more treated than untreated disease (ft/dt).

All things being equal, this demonstrates that the NHIL reform has played some role in improving the oral health of children in Israel, arguably by increasing utilization and access to dental care, and thus also arguably improving the quality of life of children and families. Indeed, dental treatment can alleviate the pain, infection, and other medical and social sequelae of active dental caries in children [3]. This is an important lesson for a country like mine, Canada, where advocacy continues in regards to improving access to dental care for socially and economically marginalized populations. Natapov, Sasson and Zusman's findings ultimately suggest that universal coverage, and more specifically, expansions to targeted public coverage, can alleviate the consequences of such market failures. To be sure, we have long known that providing public coverage is a good thing, and that depending on markets to distribute some social goods, like health care, is not always positive, much less efficient at reducing disease and associated inequalities [4].

In this regard, it is important to stress that inequalities remain for Israel's children, and may always. Yet with universal coverage, there is an opportunity to reduce them. Other opportunities also exist here as well, and Natapov, Sasson and Zusman are sage in noting the important role of school dental services, drinking water fluoridation, and other primary preventive measures, such as the engagement of the primary care and educational sectors in oral disease prevention and oral health promotion.

\section{Conclusions}

Natapov, Sasson and Zusman's findings are good evidence that the NHIL reform has helped Israel's children and their families. Yet, the authors make no direct mention of the social determinants of health, and largely maintain a behavioural focus, even though evidence is mounting that improvements in population health and oral health will further materialize by concentrating on structural level determinants (e.g. income security - reliable access to a sufficient income; fair income distribution - the equality with which income is distributed in a society; fair employment and working conditions - equal access to safe work with decent wages; food security - reliable access to affordable and nutritious food; and affordable housing reliable access to affordable shelter based on the median household income of a country) $[5,6]$. And this is a lesson that liberal democracies, including Israel and Canada, have seemed to have forgotten or choose to ignore, but that they need to re-learn or re-focus on if the goal is to have the healthiest and most productive societies possible.
Abbreviations

Dmft: Decayed, missing, and filled teeth; NHIL: National Health Insurance Law

Acknowledgments

None.

Funding

Not applicable.

Availability of data and materials

Not applicable.

Author contributions

Not applicable.

Commentary on

This is a commentary on Israel Journal of Health Policy Research article DOI: 10.1186/s13584-016-0086-3.

\section{Competing interests}

The author declares that he/she has no competing interests.

\section{Consent for publication}

Not applicable.

Ethics approval and consent to participate Not applicable.

Received: 12 September 2016 Accepted: 20 October 2016 Published online: 31 October 2016

References

1. Napatov L, Sasson A, Zusman SP. Does the dental health of 6-year-olds reflect the reform of the Israeli dental care system? Israel Journal of Health Policy Research. 2016:XX. doi: 10.1186/s13584-016-0086-3.

2. The Challenge of Oral Disease - A call for global action. The Oral Health Atlas. 2nd ed. Geneva: FDI World Dental Federation; 2015.

3. Canadian Academy of Health Sciences. Improving Access to Oral Health Care for Vulnerable People Living in Canada. Ottawa: Canadian Academy of Health Sciences; 2014.

4. Hart JT. The inverse care law. Lancet. 1971;297(7696):405-12.

5. Closing the Gap in a Generation. Health Equity through Action on the Social Determinants of Health. Final Report of the Commission on Social Determinants of Health. Geneva: World Health Organization; 2008.

6. Sgan-Cohen HD, Evans RW, Whelton H, Villena RS, MacDougall M, Williams DM, Steering IG, Williams DM, Clarkson J, Cohen L, Fox C. IADR Global Oral Health Inequalities Research Agenda (IADR-GOHIRA ${ }^{\circledast}$ ) A Call to Action. J Dental Res. 2013:92(3):209-11.

Submit your next manuscript to BioMed Central and we will help you at every step:

- We accept pre-submission inquiries

- Our selector tool helps you to find the most relevant journal

- We provide round the clock customer support

- Convenient online submission

- Thorough peer review

- Inclusion in PubMed and all major indexing services

- Maximum visibility for your research

Submit your manuscript at www.biomedcentral.com/submit 